\title{
Cost-Effective Home Mechanical Ventilation in Neurosurgery Patients: Case Series of Three Patients
}

\author{
Deepak Agrawal ${ }^{1, \odot}$ PS Chandra ${ }^{1}$ PK Singh ${ }^{1} \quad$ R Meena $^{1} \quad$ R Doddamani $^{1} \quad$ A Jagdevan ${ }^{1} \quad$ S Mishra $^{1}$ \\ K Garg ${ }^{1}$
}

${ }^{1}$ Department of Neurosurgery \& Gamma-Knife, All India Institute of Address for correspondence Deepak Agrawal, MCh, Department of Neurosurgery \& Gamma-Knife, All India Institute of Medical Medical Sciences, New Delhi, India Sciences, New Delhi, 110029, India (e-mail:drdeepak@aiims.edu).

J Neurosci Rural Pract 2020;11:329-332

\begin{abstract}
Keywords

- cost-effective

- developing countries

- home mechanical ventilation

- ventilator-associated pneumonia

Background Neurological patients who are ventilator-dependent occupy scarce beds in the hospitals for prolonged periods of time. Most, if not all, can be discharged on home mechanical ventilation (HMV). However, due to lack of insurance and state support, it remains prohibitively expensive for the vast majority of those who require it most.

Materials and Methods The authors discuss three patients admitted in the Department of Neurosurgery between January and August 2019, who were discharged on HMV after remaining on ventilator support for prolonged period in the hospital. Each patient was discharged with two units (one as standby) of AgVa home ventilator (AgVa Healthcare; New Delhi, India), one Ambu-bag, one pulse oximeter, and one backup power supply unit capable of supplying power to ventilator for a minimum of 24 hours. All the equipment were given free-of-cost through donations by hospital staffs and other donors. All patients were followed up telephonically from their homes and the incidence of complications, ventilator malfunction, and additional cost of HMV on the families were ascertained.

Observation and Results Of the three patients, two were male and one female. Age ranged from 12 to 17 years. The duration of in-hospital ventilator support prior to discharge on HMV varied from 1 to 5 years. There was no insurance cover available for any of the patients with all expenses being "out of pocket." The equipment cost Indian Rupees (INR) 115,700 (USD 1,615: two units of AgVa home ventilator costing INR 100,000 [USD 1,396], one Ambu-bag costing INR 1,100 [USD 15], one pulse oximeter costing INR 1,600 [USD 22], and one backup power supply unit costing INR 13,000 [USD 182]). Discharge on HMV was planned on specific request from patients' families and informed consent was taken from all. All patients had tracheostomies. Mode of HMV was pressure support ventilation in all. Telephonic follow-up ranged from 1 to 7 months. The cost of disposables was INR 100 per month (USD 0.7) for all the patients. No complications occurred in any patient. There was no incidence of ventilator-associated pneumonia (VAP) or ventilator malfunction.

Conclusions Availability of cost-effective indigenous ventilator like AgVa home has made HMV possible, even for poor patients with neurological diseases, and has the potential to improve quality of life, decrease VAP rates, and free up scarce ventilator beds in hospitals. Longer-term follow-up in larger number of patients will improve the data on safety and feasibility in developing countries like India.
\end{abstract}

DOI https://doi.org/

10.1055/s-0040-1709256

ISSN 0976-3147.
(C)2020 Association for Helping Neurosurgical Sick People
License terms

(요 (1) $\circledast$ 


\section{Introduction}

Prolonged mechanical ventilation (MV) is defined as the need of MV for 6 or more hours per day for 21 consecutive days. ${ }^{1}$ A patient is said to be ventilator dependent when there is failure to wean the patient from MV prior to hospital discharge. ${ }^{2}$ The neurological causes for prolonged MV include high cervical spinal cord injury (traumatic or iatrogenic), traumatic brain injury, and disease states like motor neuron disease, muscular dystrophies, myotonic dystrophy, and amyotrophic lateral sclerosis. ${ }^{3}$ In developing countries like India, with increasing pollution and life expectancy, a significant number of patients with respiratory diseases are requiring home mechanical ventilation (HMV).

Patients who are ventilator dependent use disproportionate amount hospital resources and also occupy beds, decreasing patient turnover, and may become carriers of multidrug-resistant organisms with increased potential to cross-infect other patients. Most of these patients on prolonged MV can be discharged on HMV. However, due to lack of insurance and state support, they continue to occupy scarce intensive care unit beds in public health facilities. We describe the successful discharge of three patients on prolonged MV from Neurosurgery ward to HMV.

\section{Materials and Methods}

In this case series, three patients who were discharged on HMV after remaining on ventilator support for prolonged period in the Department of Neurosurgery of our institute are discussed. Each patient was discharged with two units (one as standby) of AgVa home ventilator (AgVa Healthcare; New Delhi, India), one Ambu-bag, one pulse oximeter, and one backup power supply unit capable of supplying power to ventilator for a minimum of 24 hours. All the equipment were given free-of-cost through donations by hospital staff and other donors. All patients' families wanted to take their patient(s) home due to socioeconomic reasons and no patient was considered for HMV whose family specifically did not request for the same. Informed consent was taken from all patients/caregivers for being part of this case study. All patients were followed up telephonically from their homes and the incidence of complications, ventilator malfunction, and additional cost of HMV on the families was ascertained.

\section{Observation and Results}

Of the three patients, two were male and one female. Age ranged from 12 to 17 years. The duration of in-hospital ventilator support prior to discharge on HMV varied from 1 to 5 years ( - Table $\mathbf{1}$ ).

There was no insurance cover available for any of the patients with all expenses being "out of pocket." The equipment cost a total of Indian Rupees (INR) 115,700 (USD 1,615: two units of AgVa home ventilator costing INR 100,000 [USD 1,396], one Ambu-bag costing INR 1,100 [USD 15], one pulse oximeter costing INR 1,600 [USD 22], and one backup power supply unit costing INR 13,000 [USD 182]). All patients had tracheostomies. The mode of HMV was pressure support ventilation in all. The cost of disposables (breathing circuit) was INR 100 [USD 0.7], which was changed monthly in all patients. Telephonic follow-up ranged from 1 to 7 months. No complications occurred in any patient with no incidence of ventilator-associated pneumonia (VAP) or ventilator malfunction.

\section{Case 1}

A 13-year-old male with craniovertebral junction (CVJ) anomaly was admitted in March 2014 with progressive quadriparesis (power was $2 / 5$ in all four limbs) and underwent transoral odontoidectomy with occipito-cervical (OC) fixation. Postoperatively, he could not be weaned off the ventilator, and tracheostomy was done as he remained ventilator dependent. Over the next 4 years, he underwent multiple surgeries, including revision transoral odontoidectomy twice and implantation of phrenic nerve stimulator, which failed in improving the respiratory efforts. In August 2018, he was put on $\mathrm{AgVa}$ home ventilator and fraction of inspired oxygen $\left(\mathrm{FiO}_{2}\right)$ gradually decreased from $40 \%$ over the next few months to $21 \%$. His parents were also counselled about HMV and trained on using the AgVa home ventilator. After almost 5 years of in-hospital stay, he could be discharged in January 2019 to HMV on pressure support mode on room air $\left(\mathrm{FiO}_{2} 21 \%\right)$. He has been followed up for 7 months and continues to be stable on HMV (on AgVa home) and has had no episodes of VAP or ventilator failure in this period.

\section{Case 2}

A 14-year-old boy was admitted in March 2018 with progressive quadriparesis (power was $1 / 5$ in all four limbs) and dyspnea at rest. He had been operated 3 years back in a private hospital for CVJ anomaly and had not improved postoperatively. Patient was put on MV and underwent reexploration and OC fixation. Postoperatively, he could not be weaned off the ventilator, and tracheostomy was done as he remained ventilator dependent. In January 2019, he was put on AgVa home ventilator and $\mathrm{FiO}_{2}$ gradually decreased from $40 \%$ over the next few months to $21 \%$. His parents were also counselled

Table 1 Demographics of the patients discharged on HMV

\begin{tabular}{|l|l|l|l|l|}
\hline & Age/Sex & Diagnosis & Hospital stay & Ventilator mode \\
\hline Patient 1 & $13 / \mathrm{M}$ & CVJ anomaly & $58 \mathrm{mo}$ & PSV \\
\hline Patient 2 & $14 / \mathrm{M}$ & CVJ anomaly & $13 \mathrm{mo}$ & PSV \\
\hline Patient 3 & $17 / \mathrm{F}$ & Cervicomedullary tumor & $50 \mathrm{mo}$ & PSV \\
\hline
\end{tabular}

Abbreviations: CVJ, craniovertebral junction; F, female; HMV, home mechanical ventilation; M, male; mo, months; PSV, pressure support ventilation. 


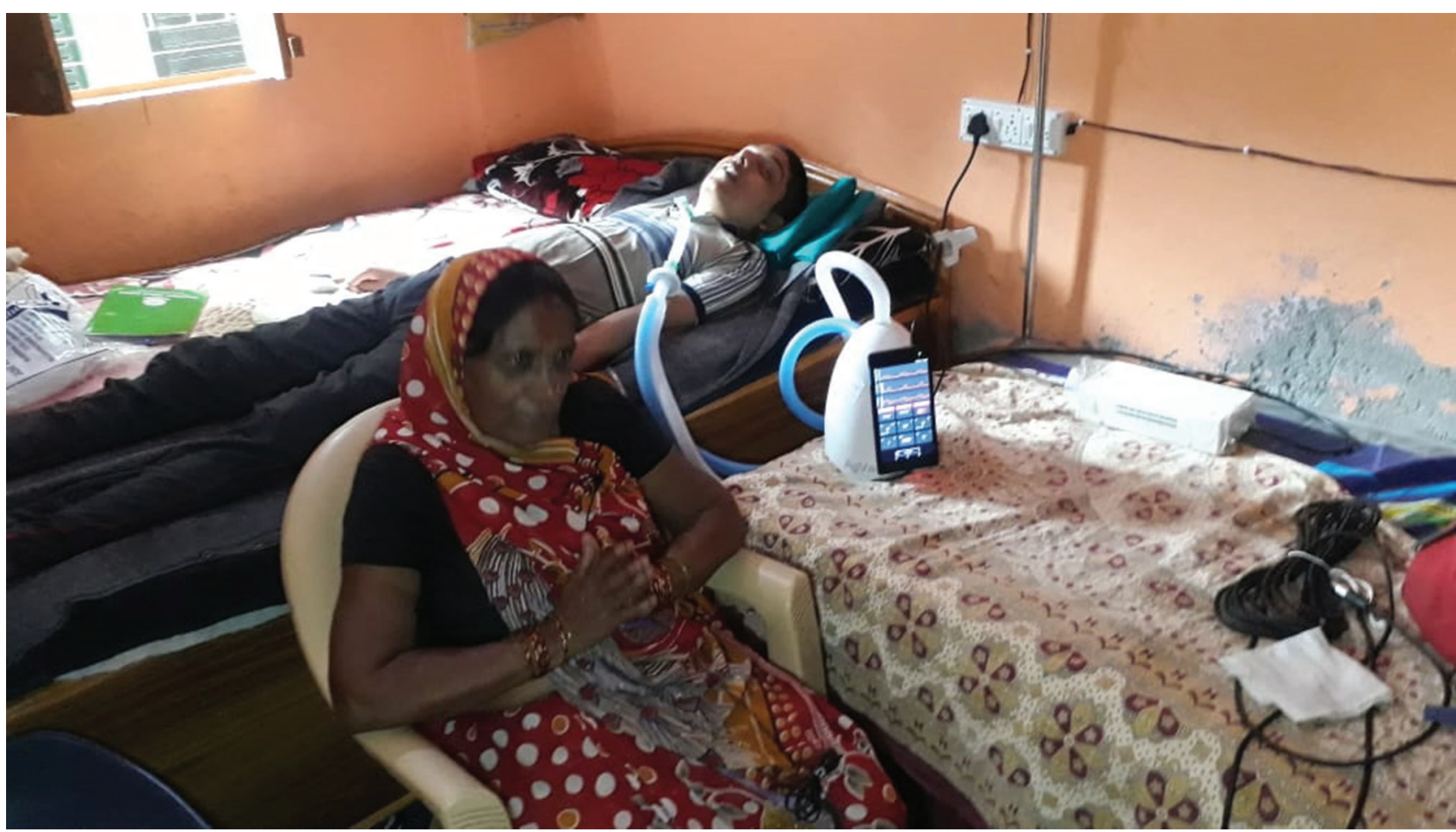

Fig. 1 Photo of Case 2 showing the patient on AgVa home mechanical ventilation.

about HMV and trained on using the AgVa home ventilator. After 1 year of in-hospital stay, he could be discharged in April 2019 to HMV on pressure support mode on room air ( $\mathrm{FiO}_{2} 21 \%$ ). He has been followed up for 5 months and continues to be stable on HMV (on AgVa home [-Fig. 1]) and has had no episodes of VAP or ventilator failure in this period.

\section{Case 3}

A 17 -year-old female presented with quadriparesis ( $3 / 5$ power in all four limbs) and was diagnosed with cervico-medullary hemangioblastoma. Following surgery, she could be weaned off the ventilator and was discharged on tracheostomy on room air. However, she was readmitted 1 month later (in July 2015) after failing decannulation and became ventilator dependent. In March 2019, she was put on AgVa home ventilator on room air $\left(\mathrm{FiO}_{2} 21 \%\right)$. Her parents were also counselled about HMV and trained on using the AgVa home ventilator. After more than 4 years of in-hospital stay, she could be discharged in August 2019 to HMV on pressure support mode on room air $\left(\mathrm{FiO}_{2} 21 \%\right)$. She has been followed up for 1 month and continues to be stable on HMV (on AgVa home) and has had no episodes of VAP or ventilator failure in this period.

\section{Discussion}

The 2015-16 National Family Health Survey (NHFS-4) showed that less than one-third (29\%) of households have any coverage under health insurance or health scheme in India. ${ }^{4}$ Despite introduction of a nationwide health insurance cover in 2018 for the economically backward families, the situation has not changed significantly on the ground. In a study performed in a central government funded teaching hospital in 2004, the total cost per day for ventilated patient was INR 10,364 of which $46.4 \%$ was borne by hospital and the rest by patients. ${ }^{5}$ Fifteen years later, the costing for a ventilator bed would have increased exponentially. Patients who are ventilator dependent also occupy scarce ventilator beds for prolonged periods of time, putting excessive strain on an already resource-constrained environment. All the patients we discharged were occupying ventilator beds for an average duration of 3 years (range $1-5$ years). In this scenario, HMV appears attractive with several benefits such as decrease in hospital-acquired infections, ${ }^{6}$ improved quality of life, ${ }^{7,8}$ significant cost-savings, ${ }^{9,10}$ improved relationships between family members and patient, ${ }^{11}$ as well as integration into the community. ${ }^{8}$

However, there are significant challenges in HMV in India; electricity supply is not constant in most parts of India with prolonged power cuts necessitating use of backup power source. In addition, due to erratic and expensive power supply, equipment like ventilators and oxygen concentrators need to be "power frugal" and able to withstand the hot and dusty climate present in this part of the world. Also, the ventilator needs to be extremely compact and user friendly so that even untrained family members can operate as well as troubleshoot issues. Most importantly, the ventilator needs to be cost-effective so that it can be made available for HMV to eligible patients.

Due to these issues, we were previously not able to consider HMV in most of the patients who were ventilator dependent for prolonged periods in our department. With the introduction of an indigenously designed and produced AgVa home ventilator, there has been a dramatic improvement in 
the availability of cost-effective ventilator care for patients in the country. AgVa home version is available in the market for INR 50,000 (USD 700), which is almost $1 / 10$ the cost of currently available portable ventilators. This version does not have oxygen inlet and runs on room air $\left(21 \% \mathrm{FiO}_{2}\right)$ consuming only $20 \mathrm{~W}$ of power. ${ }^{12}$ The ventilator is operated through an android app and is provided with a 7-inch android tablet. As most families are accustomed to using apps on smartphones, learning to operate the ventilator through the app is easier and takes an average of 4 hours for a person who has never used a ventilator before. There are no disposables except for the breathing circuit, which costs INR 100.

\section{Safety and Feasibility of HMV in Resource-Constrained Setting}

As most patients live in rural villages, hundreds of kilometers from our hospital, to allay any concerns of ventilator failure, two units of AgVa home were provided to each patient. This was mainly possible due to its cost-effectiveness. In addition, one Ambu-bag and one pulse oximeter were also provided so that desaturation could be detected and emergency ventilation continued, till troubleshooting could be done telephonically with the vendor. This care model was tested in-hospital wherein the family members were asked to operate AgVa home connected to their patient(s) for at least 1 month so that they were fully confident of using it and troubleshooting the common issues before being discharged to HMV. However, we agree that longer follow-up on larger number of patients is warranted to confirm the feasibility and safety of HMV in resource-constrained settings.

\section{Conclusions}

HMV is feasible using cost-effective indigenous ventilators even for poor families with out-of-pocket expenses, and has potential to improve quality of life, decrease VAP rates, and free up scarce ventilator beds in hospitals. Longer-term follow-up in larger number of patients will improve the data on safety and feasibility in developing countries like India.
Conflict of Interest

None declared.

\section{References}

1 MacIntyre NR, Epstein SK, Carson S, Scheinhorn D, Christopher K, Muldoon S; National Association for Medical Direction of Respiratory Care. Management of patients requiring prolonged mechanical ventilation: report of a NAMDRC consensus conference. Chest 2005;128(6):3937-3954

2 Tseng CC, Huang KT, Chen YC, et al. Factors predicting ventilator dependence in patients with ventilator-associated pneumonia. ScientificWorldJournal 2012;2012:547241

3 McKim DA, Road J, Avendano M, et al; Canadian Thoracic Society Home Mechanical Ventilation Committee. Home mechanical ventilation: a Canadian Thoracic Society clinical practice guideline. Can Respir J 2011;18(4):197-215

4 International Institute for Population Sciences (IIPS) and ICF2017. National Family Health Survey (NFHS-4), 2015-16: India. Available from http://rchiips.org/NFHS/NFHS-4Reports/ India.pdf. Accessed September 5, 2019

5 Shweta K, Kumar S, Gupta AK, Jindal SK, Kumar A. Economic analysis of costs associated with a respiratory intensive care unit in a tertiary care teaching hospital in Northern India. Indian J Crit Care Med 2013;17(2):76-81

6 Downes JJ, Boroughs DS, Dougherty J, Parra M. A statewide program for home care of children with chronic respiratory failure. Caring 2007;26(9):16-18, 20, 22-23 passim

7 Blankenburg T, Roloff D, Schädlich S, Crieé CP, Schütte W. Hypercapnic failure in patients 22. Marchese S, Lo Coco D, Lo Coco A. Outcome and attitudes toward home tracheostomy ventilation of consecutive patients: a 10-year experience. Respir Med 2008;102:430-436

8 Marchese S, Lo Coco D, Lo Coco A. Outcome and attitudes toward home tracheostomy ventilation of consecutive patients: a 10-year experience. Respir Med 2008;102(3):430-436

9 Banaszak EF, Travers H, Frazier M, Vinz T. Home ventilator care. Respir Care 1981;26(12):1262-1268

10 Bach JR, Intintola P, Alba AS, Holland IE. The ventilator-assisted individual. Cost analysis of institutionalization vs rehabilitation and in-home management. Chest 1992;101(1):26-30

11 King AC. Long-term home mechanical ventilation in the United States. Respir Care 2012;57(6):921-930, discussion 930-932

12 AgVa Healthcare. 2018. http://www.agvahealthcare.com. Accessed September 5, 2019 